\title{
Systemic lupus erythematosus, human papillomavirus infection, cervical pre-malignant and malignant lesions: a systematic review
}

\author{
Iuri Usêda Santana • Alline do Nascimento Gomes • Leomar D'Cirqueira Lyrio • \\ Maria Fernanda Rios Grassi • Mittermayer Barreto Santiago
}

Received: 20 April 2010 /Revised: 1 August 2010 /Accepted: 12 October 2010 /Published online: 31 October 2010

(C) Clinical Rheumatology 2010

\begin{abstract}
The purpose of this study was to review and evaluate systematically the scientific evidence on the relationship between systemic lupus erythematosus (SLE), human papillomavirus (HPV) infection, pre-cancerous cervical abnormalities, and cervical cancer. Establishing strict inclusion and exclusion criteria, we performed an extensive search for studies in MEDLINE and BIREME databases to assess the studies that evaluated the frequency of HPV infection, pre-cancerous cervical abnormalities, and cervical cancer in women with SLE. Secondary references were additionally obtained from the included articles. Thirty-three articles met the criteria previously established. Fifteen out of 18 studies that performed cytological analysis showed a higher frequency of squamous intraepithelial lesions in SLE patients compared with normal women. Moreover, three studies found a higher frequency of highgrade squamous intraepithelial lesions. Additionally, it was observed that women with SLE had a higher frequency of HPV infection, confirmed by molecular biology techniques. Curiously, despite the above findings, no increased frequency of cervical cancer was observed in the majority of the studies which addressed this issue. Five studies observed a relationship between cervical abnormalities
\end{abstract}

I. U. Santana - A. d. N. Gomes - L. D. Lyrio - M. B. Santiago Escola Bahiana de Medicina e Saúde Pública,

Salvador, Brazil

M. F. Rios Grassi

Centro de Pesquisas Gonçalo Moniz/Fundação Oswaldo Cruz,

Salvador, Brazil

\section{B. Santiago $(\triangle)$}

Serviço de Reumatologia do Hospital do Santa Izabel,

Praça Almeida Couto, 500, Nazaré,

Salvador, Bahia CEP 40.000-000, Brazil

e-mail: mitter@svn.com.br and previous use of immunosuppressive drugs. This review suggests that SLE patients seem not to be at increased risk for developing cervical cancer; however, they should be considered at higher risk for HPV infection and cervical dysplasia than the general population. Thus, gynecological visits at shorter intervals seem to be a reasonable approach for those patients.

Keywords Cancer Cervical intraepithelial neoplasia . Dysplasia $\cdot$ Human papillomavirus $\cdot$ Squamous intraepithelial lesion $\cdot$ Systemic lupus erythematosus

\section{Introduction}

Human papillomaviruses (HPVs) are a group of DNA viruses that can cause benign and malignant lesions in the skin and mucous membranes.

At least $15 \mathrm{HPV}$ types are associated with malignancy (high-risk HPV): HPV 16, 18, 31, 35, 39, 45, 51, 52, 56, $59,66,68,69,73$, and 83 [1]. The types 16 and 18 are the most common types found in cervical squamous cell carcinoma, accounting for more than $70 \%$ of cases [2]. While the most common low-risk types are $6,11,40,42$, $43,44,54,61,70,72$, and 81 . In general, more than $90 \%$ of the anogenital warts are associated with HPV 6 and 11 [3].

Several epidemiological and laboratory studies showed that persistent infection with HPV is strongly associated with squamous cell carcinoma and adenocarcinoma of the cervix [4]. Carcinogenesis secondary to HPV infection is due to viral integration into the host genome and the deletion of regulatory gene E2, resulting in the overexpression of E6 and E7 genes. The proteins encoded by these genes are capable of binding to tumor suppressor proteins, disrupting the cell cycle, and apoptosis [5]. 
Systemic lupus erythematosus (SLE), the prototype of the autoimmune disease is a chronic inflammatory, multisystemic disease of unknown cause. Most patients present clinical periods of exacerbation and periods of reduced activity of the disease [6]. SLE, as well as other immunological conditions, by itself or in combination with immunosuppressive therapy, theoretically may predispose the development of proliferative diseases [7-13].

A possible association between SLE and increased frequency of HPV infection, squamous intraepithelial lesions, and cervical cancer is not well defined. The aim of this study is to review and evaluate the scientific evidences on the relationship between SLE, HPV infection, pre-cancerous cervical lesions, and cervical cancer.

\section{Methods}

Inclusion criteria of the studies This review included crosssectional, case-control, retrospective, and prospective cohort studies that evaluated frequency of HPV infection, cervical abnormalities, and cervical cancer in patients with SLE.

Exclusion criteria of the studies Review articles and studies that include self-reported diagnoses were excluded.

Search strategy MEDLINE database and Biblioteca Regional de Medicina (BIREME, a specialized center of PAHO/ WHO) database were searched using the following keywords: Systemic lupus erythematosus, human papillomavirus 16, human papillomavirus 18, papillomaviridae, papillomavirus, uterine cervical neoplasm, dysplasia, neoplasia, neoplasm, intraepithelial, NIC (neoplasia intraepithelial cervical), $H P V$, pap smears, cervix carcinoma, cancer, malignancies. $\mathrm{MeSH}$, the US National Library of Medicine's controlled vocabulary used for indexing articles for MEDLINE was used. There was no restriction regarding the time of publication or language. Secondary references were additionally obtained from the included articles.

Methodology used for review After the search for articles was made, the authors independently evaluated whether the articles analyzed could be included in the review. The full articles were assessed, with the exception of five studies that were in abstract form from international meetings [14-18]. The following data were extracted: study design, sample size, number of controls, diagnostic criteria, measures of frequency of HPV infection, cervical neoplasia, cervical cancer, and the association with immunosuppressive drugs.

Classification of cervical lesions We kept the original nomenclature for cervical lesions used in each article. The cytological findings observed in Pap smear are presented as cervical dysplasia, cervical intraepithelial neoplasia (CIN), or squamous intraepithelial lesion (SIL). Currently, the 2001 Bethesda system classified the squamous epithelial lesions into two groups: low-grade squamous intraepithelial lesions (LGSIL or LSIL), which correspond to CIN I and high-grade squamous intraepithelial lesions (HGSIL or HSIL) corresponding to CIN II and III [19].

\section{Results}

From the primary search, 30 articles were selected and analyzed. Secondary search performed in these studies, resulted in the inclusion of 26 articles, ending up with 56 articles. Of these, 33 articles met the criteria previously established. The types of studies selected were with 24 cohorts (nine prospective and 15 retrospective), six crosssectional, and three case-control.

Five studies performed diagnostic techniques of molecular biology for the detection of HPV infection [15, 16, 20 23]. Nath et al. found that SLE patients as well as patients without SLE with abnormal smears had a higher prevalence of infection with HPV compared with those individuals with normal smears without SLE (15/30 in the SLE group, $37 / 67$ in abnormal smears group, and 0/15 with normal smear) [22]. Tam et al. observed a higher prevalence of infection with multiple HPV types in SLE patients compared with healthy control group $(4.7 \%$ vs. $1.1 \%)$. Moreover, the group of SLE patients showed $10.6 \%$ of high-risk HPV infection compared with $4.2 \%$ in the control group [20].

Conversely, Berthier et al. found no significant difference between latent HPV infection in the group of SLE patients compared with controls, although this may be justified by the small sample size evaluated in the SLE group [23]. SayagBoukris et al. showed 3/66 cases of latent infection by HPV in the SLE group and 6/122 cases in the control group, which was not statistically significant [16].

A higher frequency of abnormal cervical pre-malignant lesions in SLE was observed in 15 out of 18 studies that evaluated this issue (Table 1). A higher frequency of HGSIL in patients with SLE was described by Barros et al., who found 5/76 cases of HGSIL in the SLE patients and no cases in 80 control patients [24]. Similarly, Tam et al. observed $3.5 \%$ of HGSIL in a group of 85 patients with SLE compared with $0.5 \%$ in the 2,080 healthy women group [20] as well as Dhar et al., who found 13/321 cases of HGSIL or cervical cancer in the SLE group and 9/747 cases in the control group [25]. Moreover, Tam et al. noted that previous diagnosis of SLE was an independent predictive factor for abnormal Pap smears, after logistic regression analysis [20]. In a prospective cohort with a 3- 


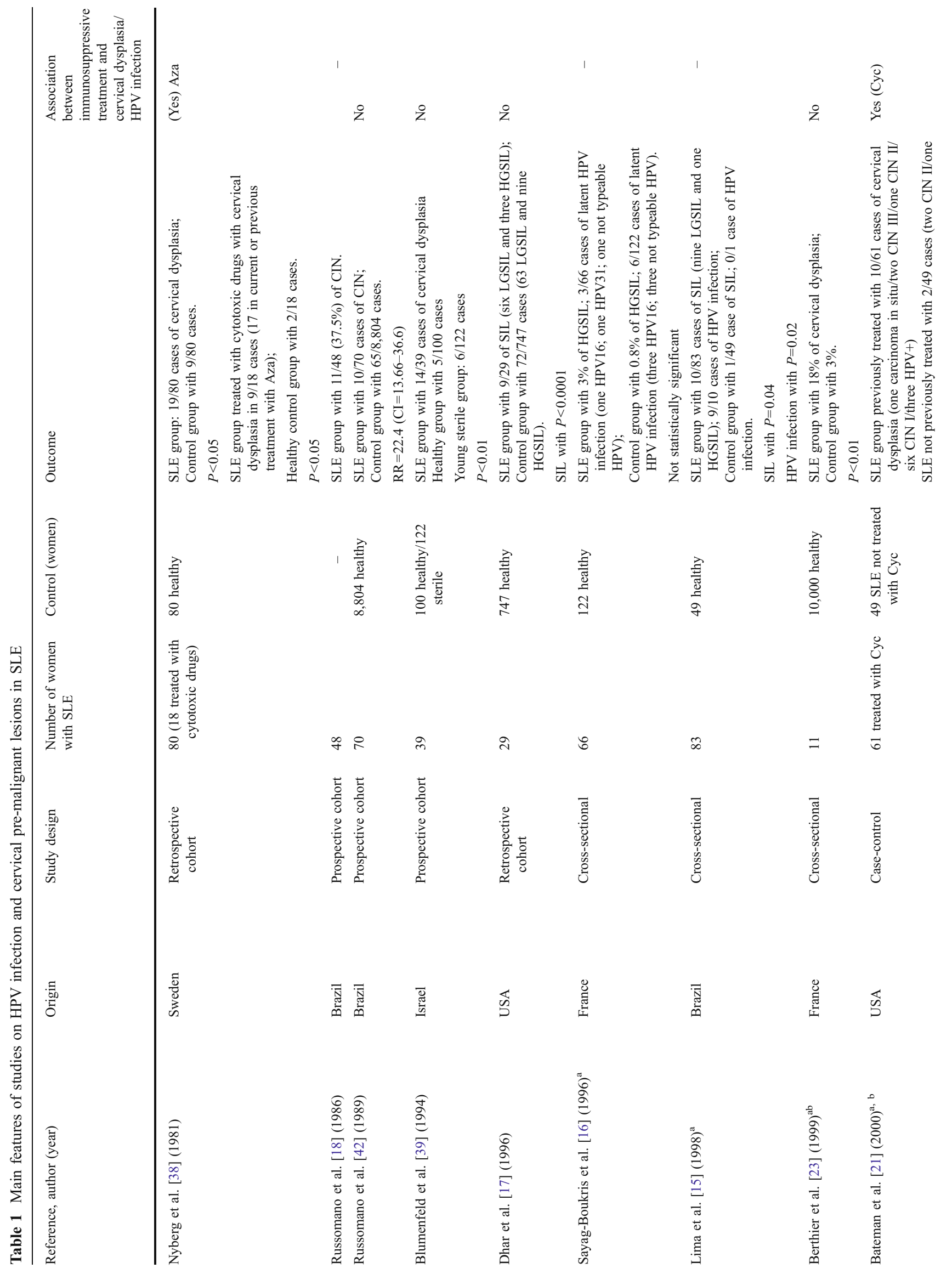




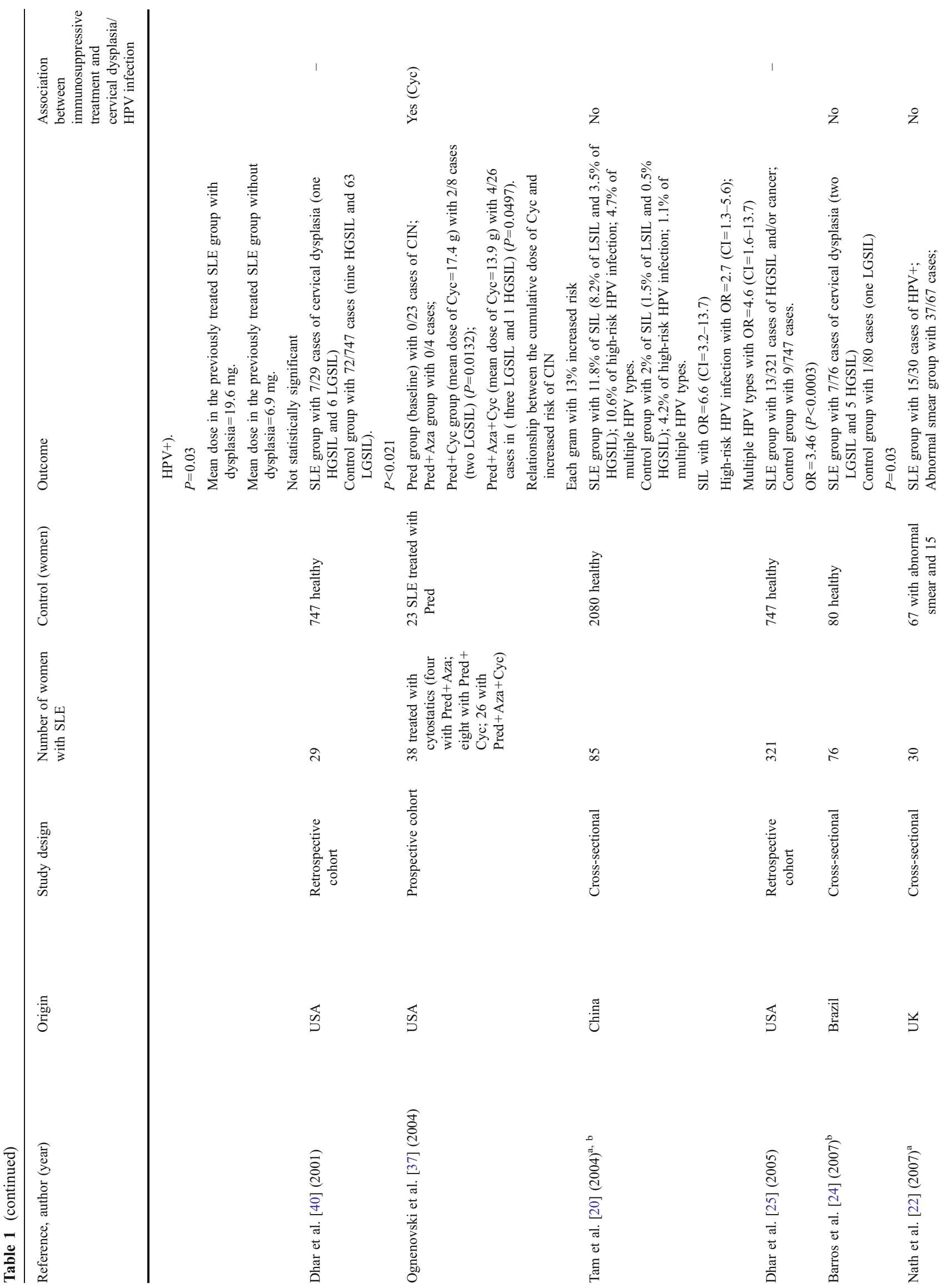


year follow-up, Tam et al. observed an increasing in the cumulative prevalence of HPV infection, high-risk HPV infection, and multiple HPV infection following-up 144 patients [26]. Only Febronio et al. did not find an increased frequency of cervical dysplasia in the SLE group, compared with control (1/52 vs. 2/52) [27].

Regarding the association between SLE and cancer, it was found that there was no increased frequency of cervical cancer in patients with SLE in 14 out of 15 articles which evaluated this association (Table 2) [7, 9-12, 14, 28-35]. Bernatsky et al. found 431 cases of malignancies being 14 of cervical cancer in a multicenter, multinational, retrospective cohort where 9,547 patients were included. This figure was similar to the normal population [32]. Likewise, four other studies found no cases of cervical cancer during the follow-up of $434,238,116$, and 39 patients with SLE, respectively [28, 29, 31, 33]. Curiously, Parikh-Patel et al. observed a reduction in the standardized incidence rate (SIR) of cervical cancer in the lupus group, compared with the expected frequency in the normal population $(\mathrm{SIR}=0.55 ; \mathrm{CI}=0.39$ 0.75) [34]. Only one study showed a higher incidence of cervical cancer in SLE comparing to the population without lupus. Cibere et al. following a cohort of 297 SLE patients, identified three cases of cervical cancer, while the incidence expected in the normal population was 0.36 cases $(\mathrm{SIR}=$ 8.15; $\mathrm{CI}=1.63-28.81)$ [36].

Three studies found a positive association between prior use of cytostatics and higher frequency of cervical abnormalities. Bateman et al. observed a higher frequency of cervical dysplasia and HPV infection in the group of SLE patients treated with intravenous cyclophosphamide as compared with the group of SLE patients without previous use of this agent: 10/61 (three positive cases of HPV infection) and 2/49 (one positive case of HPV infection), respectively. It was also observed that patients using a higher dose of this drug had a higher frequency of dysplasia. Furthermore, patients using cyclophosphamide developed cervical dysplasia in a shorter time [21]. Similarly, Ognenovski et al. found a higher incidence of CIN in the group of lupus patients treated with intravenous cyclophosphamide and prednisone and the group treated with cyclophosphamide, azathioprine, and prednisone compared with the group treated with prednisone alone (2/ 8 cases, $4 / 26$ cases versus $0 / 23$ cases). A direct relationship between the cumulative dose of cyclophosphamide and risk of cervical dysplasia was also identified. Over the initial 3year period of follow-up, a $13 \%$ increase in risk of progression from normal to CIN was observed for each gram administered [37]. Also, Nyberg et al. showed a higher incidence of cervical dysplasia in the group of SLE patients treated with cytotoxic drugs as compared with healthy control group. It was observed that $9 / 18$ cases of cervical dysplasia in the group treated with chemotherapy 


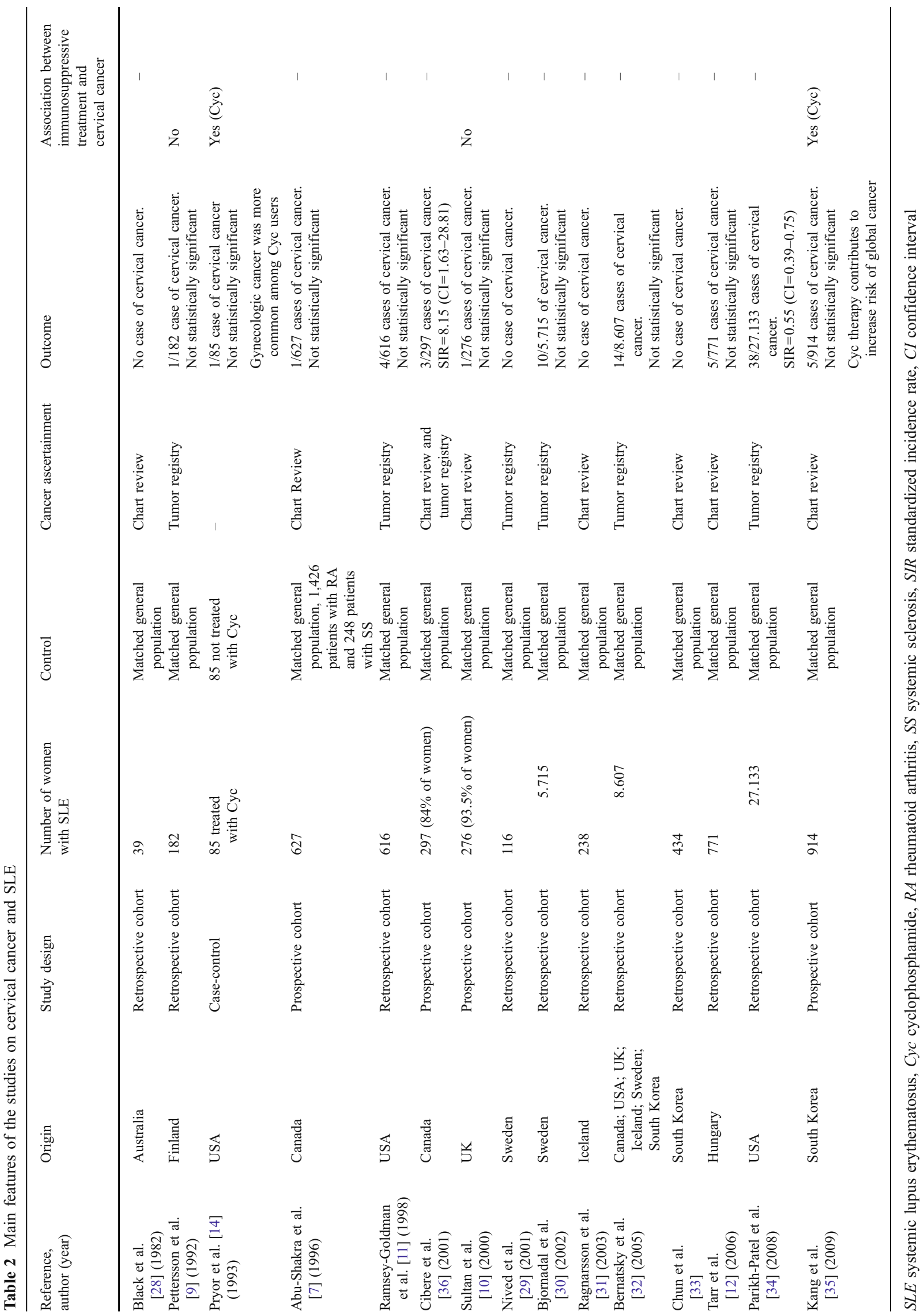


compared with $2 / 18$ cases in the control group. Seventeen among the 18 patients were in current or previous use of azathioprine, and one woman had also taken cyclophosphamide [38].

Pryor et al. observed that general gynecologic cancer was more common among cyclophosphamide users [14]. Kang et al. showed that cyclophosphamide therapy contributes to increased risk of global cancer.

On the other hand, other studies did not evaluate or find statistically significant association between cervical abnormalities and previous use of immunosuppressive drugs for the control of SLE [15-18, 20, 22-25, 39-42].

\section{Discussion}

The findings of the present systematic review suggest that SLE predisposes to SIL, which are considered to be the lesions that precede cancer, as all studies evaluating cervical changes confirmed the increased frequency of SIL in women with SLE. Even when possible confounding factors were excluded by logistic regression as it occurred in the study by Tam et al. [20], it was found that the diagnosis of SLE directly increases the risk of developing cervical lesions as revealed by Pap smear. Additionally, studies that utilized molecular biology technology for the detection of HPV were in agreement in terms of a higher frequency of HPV infection and persistence of this virus in the cervix.

There was a disagreement among different studies regarding the role of immunosuppressive drugs as a predisposing factor for these cervical abnormalities. On one side, the majority of the studies showed no association between the use of immunosuppressive agents and increased frequency of cervical abnormalities, while two others have suggested the participation of intravenous cyclophosphamide [18, 22] on the development of this complication. Nyberg et al. observed an increased incidence of cervical dysplasia in the group of SLE patients treated with azathioprine compared with the patients not treated with this drug [20]. Additionally, Kay et al. in another study - not included in the present review as it was not related to SLE- found an increased frequency of cervical dysplasia in women using azathioprine as immunosuppressive therapy after kidney transplantation [43]. The difference in the results can be explained by the small sample size evaluated in most of these studies.

A very intriguing finding from the present review was that, despite the increase in the frequency of HPV infection and cervical dysplasia in SLE patients, the frequency of cervical cancer in SLE in all studies but one was not different from the expected frequency in the normal population. Cibere et al. found an increased incidence of cervical cancer in a group of 297 SLE patients followed-up in Canada, in contrast to all other authors that evaluated the relationship between SLE and cancer. This can be explained by the smaller sample size compared with other studies and the possible increase in the search for comorbidities inherent to studies with prospective design.

The risk for other individual malignancy types such as squamous cell skin [31] and non-Hodgkin's lymphoma [32] seems to be higher in SLE. These conflicting results may be partially understood if one assumes that, once the SLE patient has the diagnosis of HPV infection or cervical abnormality, she may seek more frequently intense medical care than the normal population avoiding the development of the cancer. Additionally, few studies have utilized molecular biology techniques to determine the types of HPV to which these patients are more susceptible.

The FDA have recently approved, in the USA, two prophylactic HPV vaccines to women aged 9 to 26 years: a quadrivalent Gardasil ${ }^{\circledR}$ (MSD), which induces immune response against HPV 6, 11, 16, and 18, and a bivalent Cervarix $^{\circledR}$ (GSK), directed to HPV 16 and 18 [44]. This vaccine could not be considered an efficient prophylactic alternative to SLE patients, in spite of the possible diminished immunologic response developed by these patients against this virus.

Based on the present review, women with SLE seem not to be at elevated risk for developing cervical cancer; however, they should be considered at higher risk for HPV infection and cervical dysplasia than the general population. Thus, these patients could benefit from gynecological visits at shorter intervals.

Acknowledgements M.B.S. is currently receiving a scholarship from Conselho Nacional de Desenvolvimento Científico e Tecnológico (CNPq) and FIDEPS.

Disclosures None

\section{References}

1. Shukla S, Bharti AC, Mahata S, Hussain S, Kumar R, Hedau S et al (2009) Infection of human papillomaviruses in cancers of different human organ sites. Indian J Med Res 130(3):222-233

2. Grm HS, Bergant M, Banks L (2009) Human papillomavirus infection, cancer \& therapy. Indian J Med Res 130(3):277-285

3. Hsueh PR (2009) Human papillomavirus, genital warts, and vaccines. J Microbiol Immunol Infect 42(2):101-106

4. Bosch FX, Lorincz A, Munoz N, Meijer CJ, Shah KV (2002) The causal relation between human papillomavirus and cervical cancer. J Clin Pathol 55(4):244-265

5. Ganguly N, Parihar SP (2009) Human papillomavirus E6 and E7 oncoproteins as risk factors for tumorigenesis. J Biosci 34(1):113-123

6. Mendonça FMSF, Barbosa AD, Mendonça MSF, Duarte AP (2007) Papilomavírus humano (HPV) no lúpus eritematoso sistêmico (LES). Temas de Reumatologia Clínica 8(1):15-19

7. Abu-Shakra M, Gladman DD, Urowitz MB (1996) Malignancy in systemic lupus erythematosus. Arthritis Rheum 39(6):1050-1054 
8. Mellemkjaer L, Andersen V, Linet MS, Gridley G, Hoover R, Olsen JH (1997) Non-Hodgkin's lymphoma and other cancers among a cohort of patients with systemic lupus erythematosus. Arthritis Rheum 40(4):761-768

9. Pettersson T, Pukkala E, Teppo L, Friman C (1992) Increased risk of cancer in patients with systemic lupus erythematosus. Ann Rheum Dis 51(4):437-439

10. Sultan SM, Ioannou Y, Isenberg DA (2000) Is there an association of malignancy with systemic lupus erythematosus? An analysis of 276 patients under long-term review. Rheumatol (Oxford) 39 (10):1147-1152

11. Ramsey-Goldman R, Mattai SA, Schilling E, Chiu YL, Alo CJ, Howe HL et al (1998) Increased risk of malignancy in patients with systemic lupus erythematosus. J Investig Med 46(5):217-222

12. Tarr T, Szekanecz E, Zeher M, Szegedi G, Kiss E (2006) The occurrence of malignancies in a Hungarian lupus population. Orv Hetil 147(46):2229-2233

13. Lewis RB, Castor CW, Knisley RE, Bole GG (1976) Frequency of neoplasia in systemic lupus erythematosus and rheumatoid arthritis. Arthritis Rheum 19(6):1256-1260

14. Pryor B, Bologna S, Ernst C, Michalski S, Kahl L (1993) Risk of malignancy in cyclophosphamide-treated SLE patients. Arthritis Rheum 36:S91

15. Lima FR, Guerra D, Sella EMC, Tacla M, Fonseca AM, Bonfa E (1998) Systemic lupus erythematosus and cervical intraepithelial neoplasia. Arthritis Rheum 41(9):S202

16. Sayag-Boukris V, Menkes CJ, Charrier A, Jullian E, Coste J, Landowski P et al (1996) Risk of genital cancer in women with systemic lupus erythematosus. Arthritis Rheum 39:S213

17. Dhar JP, Kmal D, Singh G, Christianson C, Poland-Laken M, Ager J et al (1996) Cervical dysplasia in women with lupus. Arthritis Rheum 39:S69

18. Russomano FB, Serzedello MA, Reis AFF, Horta ALA, Papi JAS, Sanches LR (1986) Doenças do tecido conjuntivo: grupo de alto risco para neoplasia cervical uterina? Rev Bras Ginecol Obstet 8:224

19. Solomon D, Davey D, Kurman R, Moriarty A, O'Connor D, Prey $M$ et al (2002) The 2001 Bethesda system: terminology for reporting results of cervical cytology. JAMA 287(16):2114-2119

20. Tam LS, Chan AY, Chan PK, Chang AR, Li EK (2004) Increased prevalence of squamous intraepithelial lesions in systemic lupus erythematosus: association with human papillomavirus infection. Arthritis Rheum 50(11):3619-3625

21. Bateman H, Yazici Y, Leff L, Peterson M, Paget SA (2000) Increased cervical dysplasia in intravenous cyclophosphamidetreated patients with SLE: a preliminary study. Lupus 9(7):542544

22. Nath R, Mant C, Luxton J, Hughes G, Raju KS, Shepherd P et al (2007) High risk of human papillomavirus type 16 infections and of development of cervical squamous intraepithelial lesions in systemic lupus erythematosus patients. Arthritis Rheum 57 (4):619-625

23. Berthier S, Mougin C, Vercherin P, Desmurs H, Gil H, de Wazieres B et al (1999) Does a particular risk associated with papillomavirus infections exist in women with lupus? Rev Méd Interne 20(2):128-132

24. Barros BRC, Matschinske R, Silva MB, Skare TL (2007) Prevalence of abnormal pap smears in patients with systemic lupus erythematosus. Rev Bras Reumatol 47(5):325-329

25. Dhar JP, Essenmacher L, Ager J, Sokol RJ (2005) Ominous cervical cytopathology in women with lupus. Int $\mathrm{J}$ Gynaecol Obstet 89(3):295-296
26. Tam LS, Chan PK, Ho SC, Yu MM, Yim SF, Cheung TH et al (2010) Natural history of cervical papilloma virus infection in systemic lupus erythematosus - a prospective cohort study. J Rheumatol 37(2):330-340

27. Febronio MV, Pereira RM, Bonfa E, Takiuti AD, Pereyra EA, Silva CA (2007) Inflammatory cervicovaginal cytology is associated with disease activity in juvenile systemic lupus erythematosus. Lupus 16 (6): $430-435$

28. Black KA, Zilko PJ, Dawkins RL, Armstrong BK, Mastaglia GL (1982) Cancer in connective tissue disease. Arthritis Rheum 25 (9):1130-1133

29. Nived O, Bengtsson A, Jonsen A, Sturfelt G, Olsson H (2001) Malignancies during follow-up in an epidemiologically defined systemic lupus erythematosus inception cohort in southern Sweden. Lupus 10(7):500-504

30. Bjornadal L, Lofstrom B, Yin L, Lundberg IE, Ekbom A (2002) Increased cancer incidence in a Swedish cohort of patients with systemic lupus erythematosus. Scand J Rheumatol 31(2):66-71

31. Ragnarsson O, Grondal G, Steinsson K (2003) Risk of malignancy in an unselected cohort of Icelandic patients with systemic lupus erythematosus. Lupus 12(9):687-691

32. Bernatsky S, Boivin JF, Joseph L, Rajan R, Zoma A, Manzi S et al (2005) An international cohort study of cancer in systemic lupus erythematosus. Arthritis Rheum 52(5):1481-1490

33. Chun BC, Bae SC (2005) Mortality and cancer incidence in Korean patients with systemic lupus erythematosus: results from the Hanyang lupus cohort in Seoul, Korea. Lupus 14(8):635-638

34. Parikh-Patel A, White RH, Allen M, Cress R (2008) Cancer risk in a cohort of patients with systemic lupus erythematosus (SLE) in California. Cancer Causes Control 19(8):887-894

35. Kang KY, Kim HO, Yoon HS, Lee J, Lee WC, Ko HJ et al (2010) Incidence of cancer among female patients with systemic lupus erythematosus in Korea. Clin Rheumatol 29(4):381-388

36. Cibere J, Sibley J, Haga M (2001) Systemic lupus erythematosus and the risk of malignancy. Lupus 10(6):394-400

37. Ognenovski VM, Marder W, Somers EC, Johnston CM, Farrehi JG, Selvaggi SM et al (2004) Increased incidence of cervical intraepithelial neoplasia in women with systemic lupus erythematosus treated with intravenous cyclophosphamide. J Rheumatol 31 (9): $1763-1767$

38. Nyberg G, Eriksson O, Westberg NG (1981) Increased incidence of cervical atypia in women with systemic lupus erythematosus treated with chemotherapy. Arthritis Rheum 24 (5):648-650

39. Blumenfeld Z, Lorber M, Yoffe N, Scharf Y (1994) Systemic lupus erythematosus: predisposition for uterine cervical dysplasia. Lupus 3(1):59-61

40. Dhar JP, Kmak D, Bhan R, Pishorodi L, Ager J, Sokol RJ (2001) Abnormal cervicovaginal cytology in women with lupus: a retrospective cohort study. Gynecol Oncol 82(1):4-6

41. Mercado U (2009) Squamous intraepithlelial lesions in women's lupus. Ginecol Obstet Méx 77(9):423-427

42. Russomano FB, Serzedello MA, Reis AFF, Horta ALA, Papi JAS, Sanches LR (1989) Involved factors in the association lupus erythematosus-cervical neoplasia. Rev Bras Ginecol Obstet 11 (12):238-242

43. Kay S, Frable WJ, Hume DM (1970 Nov) Cervical dysplasia and cancer developing in women on immunosuppression therapy for renal homotransplantation. Cancer 26(5):1048-1052

44. Balofsky A, Agmon-Levin N, Shoenfeld Y (2010) The new H1N1 and HPV vaccines and old fears. Curr Opin Rheumatol 22 (4):431-436 